\title{
PARA JAIME RUBIO, TODAVÍA
}

\author{
Francisco Sierra Gutiérrez* \\ doi:10.11144/Javeriana.uph33-66.pjrt
}

CON GRAN APRECIO Y RESPETO, inicio con una graciosa evocación:

- Hola, Jaime, ¿cómo estás?

- "Bien, como para no preocuparlo". Y, en otras oportunidades respondía:

- "Ahí..., como cuando Ud. era pobre".

Sí, PARA JAIME RUBio, una vez más pero, ahora, desde la memoria sentida de ya una década, de sus hijos, familiares, amigos, estudiantes, colegas, allegados; de sus coetáneos; de todos aquellos en quienes todavía la memoria individual sigue siendo fiel guardiana de buenas conversaciones, anécdotas, detalles, gestos, hondos sentimientos, nostalgias irresolubles, invectivas y gracejos, pesimismos confesos, enseñanzas profundas, ideas enigmáticas, porvenires distantes, nombres y obras de filósofos desconocidos, e ironías agudas para resistir a cuanta imbecilidad política y social aconteciera de forma agobiante día tras día.

Sí, una vez más pero, ahora, como memoria colectiva de su vida y de su obra, en el difícil tránsito hacia su incorporación en la narrativa del patrimonio de nuestra memoria histórico-filosófica colombiana, y que anhela sobrevivir más allá de sus contemporáneos. Para eso, he aquí una obra póstuma, una huella

* Pontificia Universidad Javeriana, Bogotá, Colombia.

Correo electrónico: fsierra@javeriana.edu.co

Para citar este artículo: Sierra Gutiérrez, F. (2016). Para Jaime Rubio, todavía. Universitas Philosophica, 33(66), pp. 309-315. ISSN 0120-5323, ISSN en línea: 2346-2426, doi:10.11144/ Javeriana.uph33-66.pjrt 
material "abierta a todo aquel que sepa leer" que Jaime ha urdido -no sabemos cómo- hasta verla realidad.

Con Regocijada gratitud presento mi saludo al Dr. Nicolás Morales, por su decidido respaldo a este proyecto como Director del prestigioso Sello: Editorial Pontificia Universidad Javeriana; a Rafael Rubio y a Jhon Jairo Mesa, como asistentes editoriales que, junto con la correctora de estilo, Laura Giraldo, y a la diagramadora, Claudia Patricia Rodríguez, aceleraron la imprenta de Javegraf como un Ferrari Fórmula Uno en la recta final, para entregarnos esta obra en nuestras manos esta tarde, 8 de octubre de 2015. A Juanita y a Diego, hijos de Jaime, mi honda gratitud por aplaudir de inmediato con su autorización escrita el deseo de publicar este texto. A nuestro Decano, Dr. Diego Pineda y al Secretario de Facultad, Dr. Justiniano Perdomo, por su apoyo, disposición y gestión financiera para esta iniciativa. Y, también quisiera hacer explícito mi sentido de gratitud y de reconocimiento sinceros con Anna Valentina Beltrán Sánchez, por digitalizar con prontitud el documento que estaba en casi ilegibles fotocopias; a Carlos Arturo Arias Sanabria, por su diligente, esmerada y eficaz asistencia editorial perfeccionando y normalizando cada día el escrito, y a Airlén María Durán Acosta, que desde Valledupar nos remitió fotocopias de sus fotocopias con los subrayados de su acucioso estudio y el inevitable corrugado del calor soporífero en las tintas.

A LA PREgUnTA que ya trae entre labios este respetable auditorio sobre qué ha pasado desde entonces con las posiciones filosóficas de Jaime, habría que responder de entrada, por una parte, que estas ya han sido objeto (hasta donde conozco) de dos trabajos de grado, uno de pre-grado y otro de Maestría, en dos universidades distintas. Que se lo cita con cierta frecuencia en artículos que reflexionan sobre el filosofar actual en Colombia y en América Latina, y que sus enseñanzas perviven en la memoria de sus estudiantes y colegas, así como en sus actividades docentes e investigativas. Que el pensamiento de Ricœur, Jolif, Gadamer y, de otros más cuyo mediador era Rubio, ya es de algún modo mentado o familiar entre nosotros. Por 
otra parte, si bien en vida de Jaime no logramos algunos profesores que, en una de las últimas reformas del plan de estudios de la carrera de filosofía en la Javeriana se abriera una cátedra específica sobre filósofos colombianos y latinoamericanos (propuesta que mantengo vigente), esto no puede llevar de ninguna manera al equívoco de que de esta forma nos hemos desembarazado, fácilmente y para siempre, de la exigencia crucial de que toda comprensión filosófica nos auto-involucra existencial, local y territorialmente.

Por el contrario, estudiantes y profesores exploran nuevos caminos, mediaciones, pensadores, intereses y circunstancias para atender a ella, en esta o en otras instituciones. Para mencionar tan solo unos ejemplos de problemáticas que se investigan en nuestra facultad (y de los que revelo el milagro, mas no el santo), y con la venia anticipada de los que olvido o no alcanzo a mencionar:

- ¿Cómo no advertir que en las Suplicantes de Esquilo y de Eurípides, en que es puesta a prueba la democracia cuando los gobernantes no atinan soluciones justas que conjuguen sabiamente normas estrictas con exigencias humanas concretas, se traen ideas y propuestas para un buen gobierno y para enrostrar la legítima defensa de las mujeres y de sus derechos tan pisoteados diariamente en nuestras ciudades, en las familias, en colegios y en universidades, y el papel que juega una sociedad civil activa en su defensa?

- ¿Cómo pasar de largo ante la perspectiva geopolítica del filosofar, cuando con las mediaciones categoriales y ontológicas de Foucault, Deleuze, Agamben o Rancière, se nos revela la ontología histórica de nosotros mismos en los raizales nudos y desnudos de Tumaco, de Buenaventura o del Chocó; o se devela la noción de pueblo en la Bogotá de los años veinte del siglo pasado con su "revolución de la chicha"; o, nos causa asombro la "hybris del punto cero" y la "crítica de la razón latinoamericana", o deconstruimos desde esta meseta el entusiasmo crítico-ideológico de un esloveno?

- ¿Cómo no reconocer que en la Biblioteca Virtual del Pensamiento Filosófico en Colombia, desde la Colonia hasta nuestros días, tenemos no solo una muestra de la apropiación y novedad del filosofar en nuestra región, sino toda una gran veta investigativa y propositiva?

- ¿Cómo no vernos confrontados y casi apabullados con los dardos certeros de un Nicolás Gómez Dávila, o con la potente vitalidad del pensamiento 
caribeño, o con el desgarramiento que el mal y el sufrimiento humano nos provoca?

- ¿Cómo no reivindicar el pensamiento y la estructuración del discurso desde las culturas populares próximas y sus modos de sentir, significar y hablar cotidianos?

- ¿Cómo no estar urgidos de reflexión y de discusión por el ejercicio de la violencia mimética en nuestras instituciones, el desgreño moral y ético de las empresas y de los gobernantes, y no esperar -sin un buen escepticismo- cambios significativos de horizonte de nuestra historia colombiana más reciente?

Permítanme SEÑAlar, finalmente, solo dos lugares (de otros muchos, quizá), en los que el debate filosófico de las ideas de Rubio sigue abierto. En primer lugar, la declaración de raigambre ricœriana en los primeros renglones de esta su obra póstuma, con la que da razón de por qué hablar del trabajo hermenéutico como un acto de reapropiación de sí que el sujeto realiza sobre las obras en que expresa su deseo de ser y su esfuerzo por existir. Rubio (2015) escribe:

Porque el 'yo' del 'yo pienso' no se comprende a sí mismo como sujeto de las operaciones de conocimiento, volición, estimación, entre otros; o, para decirlo más radicalmente, no hay coincidencia entre ser y conocer. El sujeto se produce y luego se conoce; en consecuencia, no hay comprensión de sí que no esté mediada por los signos, los símbolos y los textos. La comprensión de sí coincide con la interpretación de los términos mediadores. (p. 13)

Esto me retrotrae o me repite algunos apartes de discusiones sostenidas con él años antes de su partida y que hoy día se hacen más álgidas, toda vez que, o bien, el sujeto permanece oculto bajo el principio de inmanencia; o se lo (nos) sitúa como resultado de las prácticas discursivas, de los dispositivos de poder, construido por una historia solo en términos de subjetividades y de sujeciones; o se lo configura cual proceso maquínico de un animal complejo. Todo ello hace más relevante el interrogante acerca de quiénes son (somos) los sujetos de la emancipación; quiénes son los que van a acometer la tarea de reinventarse en, a través de y a pesar del laberinto de su historicidad y sujeción; quiénes son los que 
pueden aún responder con la ontología del "heme aquí" (Ricœur) en situaciones poscoloniales del saber y pre-postcapitalistas del hacer; quiénes son los que no hacen parte de los que ya tienen parte pero están ahí; en fin.

En este debate, mi opción, igualmente discutible, se remonta al canadiense Lonergan que ha escrito que:

El sujeto-en-cuanto-sujeto es la realidad en el sentido que vivimos y morimos, amamos y odiamos, nos regocijamos y sufrimos, anhelamos y tememos, esperamos y soñamos, investigamos y dudamos. Se trata del cogito de Descartes traspuesto a la vida concreta. Es el sujeto mismo no como expuesto en una teoría o afirmación de la conciencia, sino como el pre-requisito prioritario de cualquier presentación, como condición a priori de cualquier flujo de conciencia (incluidos los sueños).

$\mathrm{El}$ argumento consiste en que lo prioritario no es el objeto-en-cuanto-objeto o el sujeto-en-cuanto- objeto; solo queda el sujeto-en-cuanto-sujeto, y este sujeto-en-cuanto-sujeto es simultáneamente realidad y algo a descubrir mediante la conciencia. El argumento no prueba que en el sujeto-en- cuanto-sujeto podamos encontrar la evidencia, las normas, las constantes y los principios para una crítica de los horizontes; prueba que, a menos que encontremos allí al sujeto, quizás nunca lo descubramos del todo. (Lonergan, 2001, p. 215)

Por hacer tan solo un breve comentario de esta cita, ella apunta a la emancipación de connotaciones inmanentistas de la subjetividad, pues se arraiga en la base en marcha de nuestros dinamismos existenciales conscientes e intencionales, en las diferentes configuraciones de nuestra experiencia situada y, sin ocultar su polimorfismo recurrente, suministra un modo abierto y en tensión de nuestra auto-presencia irrebasable y siempre inadecuada; ese centro frágil de inmediatez en que quizá reconozcamos la coloquial expresión: "llueva, truene o anochezca y... el 'gringo' ahí'. El canadiense no sostiene que la autoconciencia y el autoconocimiento sean una y la misma cosa. La primera está dada (de manera polimórfica e indiferenciada); la segunda no es posible sino como resultado en marcha de la objetivación siempre revisable de la primera, la que conserva en esa instancia su concomitante presencia y se apropia de la segunda. Sin esta distinción, la comprensión y la autocomprensión de la subjetividad será aun más equívoca.

El sujeto-en-cuanto-sujeto constituye entonces una unidad dialéctica de identidad y de no-identidad entre el sujeto-en-cuanto-objeto (con todo su largo 
rodeo por el camino de los símbolos y las narrativas à la Ricœur), y del objeto-encuanto-objeto (con las connotaciones del naturalismo e inmanentismo actuales). Pero esta unidad en tensión no se iguala con la identidad, de manera absoluta, como podría haberse dado en el idealismo hegeliano: porque el sujetoen-cuanto-objeto es realmente distinto del sujeto-en-cuanto-sujeto; porque la experiencia consciente inmediata nunca se sublima completamente en el conocimiento, como sí lo plantea el idealismo (Lamb, 1981).Por otra parte, el carácter real de esta distinción, de ninguna manera conduce a la absolutización de la noidentidad (como lo proclaman las distintas disoluciones del sujeto que hoy se esgrimen); porque las operaciones conscientes e intencionales del sujeto-encuanto-sujeto constituyen al sujeto-en-cuanto-objeto y ellas mismas son las mediadoras del objeto-en-cuanto-objeto, en la medida en la que toda objetividad se arraiga en una subjetividad que se auto-trasciende y se descentra. Por lo tanto, la unidad del sujeto no es absoluta, sino solo virtualmente incondicionada; es decir, en la medida y alcance en que sus condiciones se cumplan, pero estas lo van haciendo de manera contingente en el despliegue dialéctico del desarrollo intersubjetivo, individual, social y cultural en la compleja historicidad humana.

De nuevo, ¿̇iene aún sentido preguntar por quiénes son o somos los sujetos del filosofar en nuestro medio; y, qué sentido y eco tiene su quehacer en nuestro entorno más próximo?

En segundo lugar, la enjundiosa tarea de la reapropiación de sí a través de las obras que expresan nuestro deseo de ser y nuestro esfuerzo por existir, que sirve de norte al filosofar de Rubio, si bien combina magistralmente por la vía de la mediación narrativa las dimensiones hermenéutica e histórica del filosofar continental contemporáneo, a mi entender, nos pueden advertir no solo de un horizonte promisorio (que guarda relación con una hermenéutica de corte analítico), sino también de la posibilidad de otros caminos recorridos y a recorrer con los cuales pueda entablarse una cooperación creativa sin caer en eclecticismos repudiables ni en totalidades indiferenciadas.

Un despliegue diverso y sin pretensiones totalitarias que involucre perspectivas dialécticas hoy renovadas, modos de intervenir en y desde las matrices culturales, modos de ejercer una racionalidad comunicativa y discursiva, de investigar la ontología histórica de nosotros mismos y de nuestros conflictos, de explicitar un nuevo tipo de opciones filosóficas fundamentales; una nueva búsqueda de 
categorías, discursividades y cursos de acción prospectivos, unas nuevas bases de datos y de informaciones pertinentes a nuestra reflexión filosófica, unas nuevas formas de conversación, negociación, diálogo, con la diversidad de nuestros procesos socio culturales, políticos, ambientales, ciertamente nos invitan a cooperar de manera creativa y metódica, para responder con mayor tino la recurrente pregunta de qué hacemos cuando hacemos filosofía en nuestro medio, de por qué eso que hacemos es filosofía y no otra cosa, y de qué pueden hacer unos grupos humanos, una sociedad y unas culturas tan agobiadas en su historicidad con los procesos y los productos de estos modos de filosofar.

Quizá sobre este último punto, sea preciso reconocer que "todavía no nos encontramos alli", en esta forma de complementariedad, dialéctica y de posible cooperación abierta entre horizontes (que no necesariamente se fusionan). Tampoco se pretende la obligatoriedad del tener que estar allí; tan solo es un 'codazo' amable que pide salir de una estéril dispersión, que desperdicia esfuerzos y recursos, imposibilita el diálogo y encierra sin misericordia a cada horizonte y sus propuestas en una autocontradicción performativa naturalizada.

Bienvenida la hermenéutica de nuestra conciencia histórica que, de cierto modo, nos puede anunciar que en nuestro quehacer hay que prescindir de ambiciones totalitarias y opciones cerradas, para las cuales, de manera excluyente, o todo es hermenéutica, o método, o arqueo-genealogía, o dialéctica materialista, o esquemas conceptuales auto-contenidos, o solo racionalidad comunicativa procedimental, o solo deconstrucción, o solo contribución a un descomunal repositorio de acceso inmediato a la información filosófica registrada y avalada.

\section{Referencias}

Rubio, J. (2015). Hacia una hermenéutica de nuestra conciencia histórica. Bogotá: Editorial Pontificia Universidad Javeriana. Colección Anábasis.

Lamb, M.L. (1981). Methodology, Metascience, and Political Theology. Lonergan Workshop, 2, pp. 281-403.

Lonergan, B.J.F. (2001). Phenomenology and Logic: The Boston College Lectures on Mathematical Logic and Existentialism. CWL 18. Toronto: UTP. 